\title{
A Comprehensive Numerical Investigation on the Mechanical Performance of Hybrid Composite Tidal Current Turbine under Accidental Impact
}

\author{
H. Laaouidi ${ }^{*}$, M. Tarfaoui ${ }^{2}$, M. Nachtane ${ }^{3}$, M. Trihi ${ }^{1}$ and O. Lagdani ${ }^{1}$ \\ ${ }^{1} \mathrm{FSAC}$ - UH2C, Laboratory for Renewable Energy and Dynamic Systems, Morocco \\ 2ENSTA Bretagne, IRDL UMR CNRS 6027, F-29200 Brest, France \\ 3University of Bordeaux, CNRS, Arts et Metiers Institute of Technology, Bordeaux INP, INRAE, I2M Bordeaux, F-33400 Talence, France
}

\begin{abstract}
The composite tidal turbine nozzle can be exposed to impact loads during maintenance or installation operations, which may result in invisible damage. Therefore, it is very important to analyse the induced damage in order to conceive hybrid composite nozzles with better resistance to damage. The low-velocity impact behaviour (LVI) of a carbon/glass hybrid composite nozzle has been investigated based on this motivation. The configurations of stacking sequences were constituted of glass and carbon fibers. The results acquired were compared between five various laminated. Indeed, the impact was studied in the leading edge region of the nozzle. The damaged laminates were inspected by the finite element method (FEM) based on Hashin failure criterion using the ABAQUS software. The energy conservation of the nozzle was verified to validate the numerical model. Futhermore, the effect of accidental impact on dynamic response and the damage induced on a hybrid composite nozzle have been investigated. According to results, the formation of damage like matrix cracking on the external/internal surfaces and radial cracking may occur. In addition, the hybrid nozzle with CCC (carbon/carbon/carbon), and CGG (carbon/glass/glass) stacking has greater impact resistance compared to other configurations.
\end{abstract}

ARTICLE HISTORY

Received: $9^{\text {th }}$ July 2020

Revised: $6^{\text {th }}$ Oct 2020

Accepted: $2^{\text {nd }}$ Dec 2020

\section{KEYWORDS}

Current turbine;

Finite element method (FEM);

Hybrid fibres composites;

Low-velocity impact;

Dynamic behaviour

\section{NOMENCLATURE}

Symbols
$\rho$
$\sigma$
$M$
$D_{f ;} ; d_{m} ; d_{s}$
$D ; E_{1} ; E_{2} ; G_{12}$
$\vartheta_{12} ; \vartheta_{2 l}$
$X^{T} ; X^{C}$
$Y^{T} ; Y^{C}$
$S^{L} ; S^{T}$
$G_{i}$
$\delta_{i, e q}$
$\sigma_{i, e q}^{0}$
$\delta_{i, e q}^{f}$

\section{INTRODUCTION}

density

the real stress

the damage operator

the damage variables

undamaged material moduli

undamaged material Poisson's ratios

the tensile and the compressive strengths in

the direction of the fibres

the tensile and the compressive strengths in

the transverse direction

the longitudinal and the transverse shear

strengths of the composite

the energy dissipated during the propagation

of the damage

the equivalent displacement

the equivalent initial stress

the equivalent displacement inducing the

deletion of the element

$\begin{array}{ll}\text { Acromyms } & \\ \text { LVI } & \begin{array}{l}\text { low-velocity impact } \\ \text { tidal current turbine }\end{array} \\ \text { TCT } & \text { finite element method } \\ \text { FEM } & \text { renewable marine energies } \\ \text { RME } & \text { finite element analysis } \\ \text { FEA } & \text { carbon/carbon/carbon } \\ \text { CCC } & \text { glass/glass/glass } \\ \text { GGG } & \text { glass/glass/carbon } \\ \text { GGC } & \text { glass/carbon/glass } \\ \text { GCG } & \text { carbon/glass/glass } \\ \text { CGG } & \text { artificial energy } \\ \text { ALLAE } & \text { strain energy } \\ \text { ALLSE } & \text { damaging energy } \\ \text { ALLDMD } & \text { kinetic energy } \\ \text { ALLKE } & \text { total energy } \\ \text { ETOTAL } & \text { internal energy }\end{array}$

In recent years, renewable marine energy (RME) appeared like a tremendous opportunity for a truly industrial and ecological option to meet the increasing energy demands and combat global warming. Produced from marine currents, RME has been the subject of particular research interest. Indeed, several research studies [1] have shown that this type of energy has a considerable interest in terms of predictable and durable resources for generating electrical energy. The current research paper is conducted with this framework in mind. The main focus is one of the most promising categories of RMEs, the tidal current turbine (TCT). During functioning or maintenance operations, the TCT is always exposed to different types of impact. Therefore, this technology must be constructed in the most secure way possible to resist different 
loadings. There are several possibilities; one of them is to make engines more performant by using composite materials which represent so far the best compromise between performance, weight, and structural integrity [2]. Indeed, composite materials are known for their low density, excellent ratio (mass/resistance, mass/rigidity), and excellent corrosion resistance. Some studies have demonstrated that the impact extremely decreases the mechanical properties of the composite material such as matrix fissuring, fibre-matrix decohesion, fibre rupture, and delamination. For example, Nachtane et al. [3] analysed the effect of impactor shape and velocity on the dynamic behaviour and damage kinetics induced to the nozzle during operation. They compared glass fibre reinforced polyester matrix to carbon fibre reinforced epoxy matrix. They proved that every composite material employed in the simulations had its strengths and limits. Tarfaoui et al. [4] studied the effect of environmental impacts on the mechanical properties of a glass fibre reinforced polymer composite tidal turbine. The results showed that damage was observed in different zones of the structure.

The fabrication of composites from a single reinforcing fibre is generally not adapted to particularly complex loading situations $[5,6]$. Therefore, to guarantee the composite properties perfectly adapted to the needs of the considered structure, hybrid fibre composites have recently been the subject of particular attention by researchers. Some research work recently reveals that hybrid fibre-reinforced polymer composites can be used in many applications due to its excellent mechanical properties, including low weight, high corrosion resistance, and high specific strength [7]. Gemi [8] studied the low-velocity impact response of hybrid composite pipes (carbon/glass). The results show that hybrid laminate carbon/glass/glass offers higher impact resistance. Furthermore, Sun et al. [9] carried out a study on the mechanical properties of carbon/basalt composite materials; the results showed that the hybrid effect was positive for tensile and flexural strength. In general, the recourse of laminate hybridisation has demonstrated that it is possible to reduce impact damage and increase the structural performance of damaged stratified [10].

According to the literature, the application of hybrid composites in tidal turbine nozzles has never been studied. This work is a new study that aims to predict the effect of accidental impact on dynamic response and the damage induced on a hybrid composite nozzle using the finite element method (FEM). The impact was studied on the leading edge area of the nozzle, and the simulated damage is compared for different materials.

\section{MATERIAL, STRUCTURE, BOUNDARY CONDITIONS AND IMPACT SCENARIOS}

\section{Mechanical Properties of Composites and Structure}

The composite considered in this study is a hybrid laminate immersed in an epoxy resin $0.64 \mathrm{~mm}$ thick per layer [8]. The configurations of the stacking sequences have been identified in the following manner: carbon/carbon/carbon (CCC), glass/glass/glass (GGG), glass/glass/carbon (GGC), carbon/glass/glass (CGG), and glass/carbon/glass (GCG) extending from the internal to the external surface, Figure 1. The mechanical properties of the composites are represented in Table 1 , and the mass of each laminate is illustrated in Table 2.

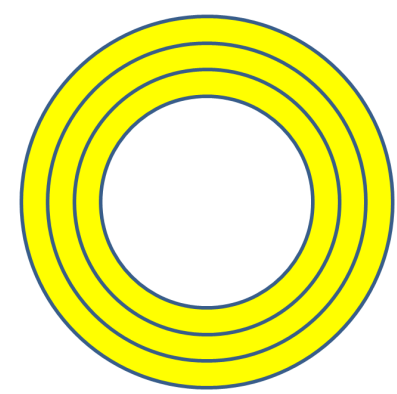

(a) GGG

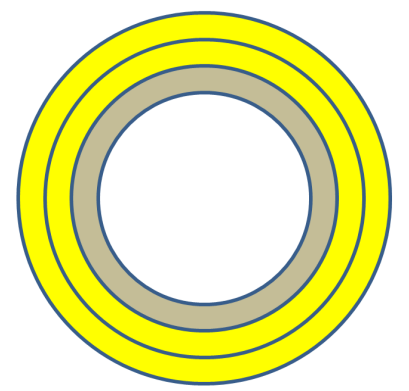

(d) CGG

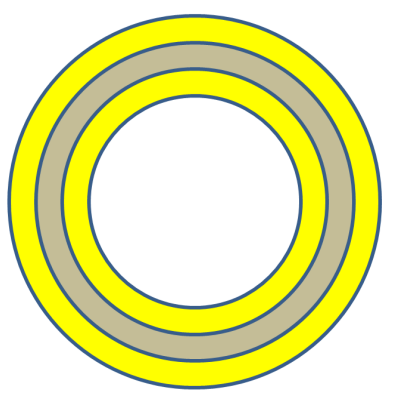

(b) GCG

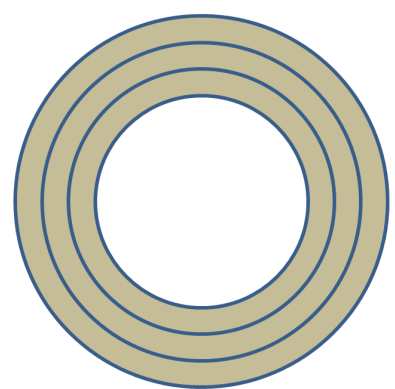

(c) $\mathrm{CCC}$

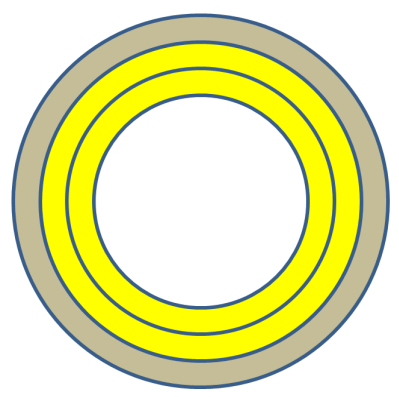

(e) GGC

Figure 1. The stacking sequence configurations.

Figure 2 and 3 shows the 3D structure of the marine turbine and its hydrodynamic profile, which was traced using Heliciel software [11]. This structure was integrated into the Abaqus software based on finite element analysis (FEA) to perform simulations of accidental impact study during installation and to predict its dynamic behaviour and mechanical performance [12]. 
Table 1. Properties of glass-epoxy and carbon-epoxy [8].

\begin{tabular}{lcc}
\hline Properties & Glass-epoxy & Carbon-epoxy \\
\hline$\rho\left(\mathrm{kg} / \mathrm{m}^{3}\right)$ & 1659 & 1238 \\
$E_{l}(\mathrm{MPa})$ & 26705 & 1928 \\
$E_{2}(\mathrm{MPa})$ & 7495 & 4598 \\
$\mathrm{Nu}_{12}$ & 0.28 & 0.32 \\
$G_{12}=G_{13}=G_{23}(\mathrm{MPa})$ & 2833 & 1729 \\
$X_{t}(\mathrm{MPa})$ & 1006 & 1429 \\
$X_{c}(\mathrm{MPa})$ & 487 & 530 \\
$Y_{t}(\mathrm{MPa})$ & 46 & 41 \\
$Y_{c}(\mathrm{MPa})$ & 132 & 145 \\
$S_{L}(\mathrm{MPa})=S_{T}(\mathrm{MPa})$ & 42 & 83.4 \\
\hline
\end{tabular}

Table 2. Mass of the tidal turbine nozzle.

\begin{tabular}{llllll}
\hline Configuration & CGG & GCG & GGC & GGG & CCC \\
\hline Mass (tons) & 16.99 & 16.99 & 16.99 & 18.57 & 13.85 \\
\hline
\end{tabular}

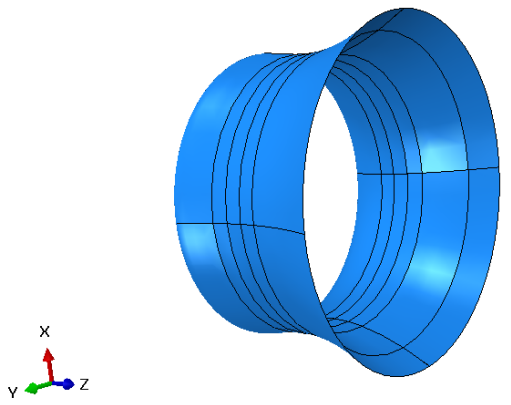

(a) CAO Part

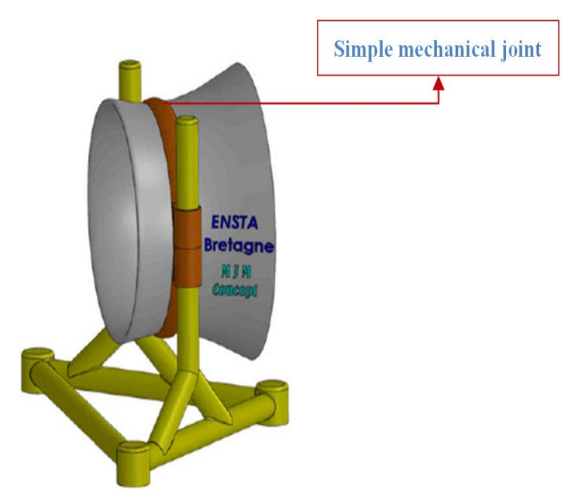

(b) Final design

Figure 2. 3D structure of the marine turbine.

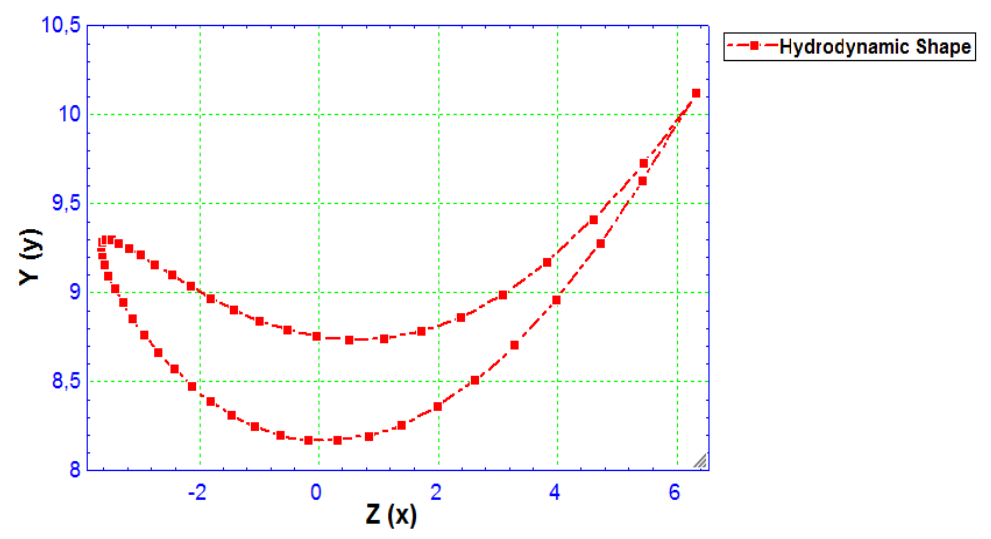

Figure 3. Hydrodynamic profile.

\section{Boundary Condition and Impact Scenario}

The tidal turbine nozzle is exposed to accidental impacts during installation. However, adequate strength and rigidity are necessary for hydrokinetics, and the only possibility is to use more resistant materials such as hybrid composite materials that offer a compromise between several parameters such as performance, durability, weight, and cost.

For the right conception of the nozzle design and to better analyse its behaviour under dynamic loading, the structure was exposed to its leading to an accidental impact. Figure 4 shows a description of the installation system. 


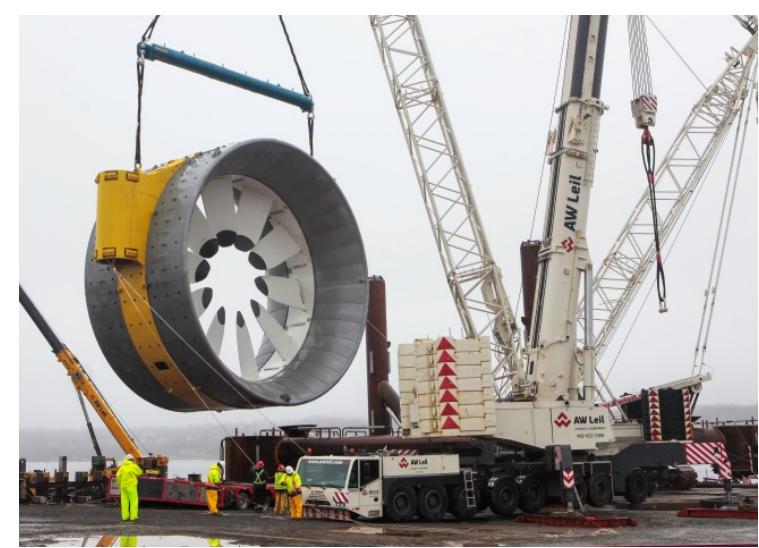

(a) tidal turbine installation

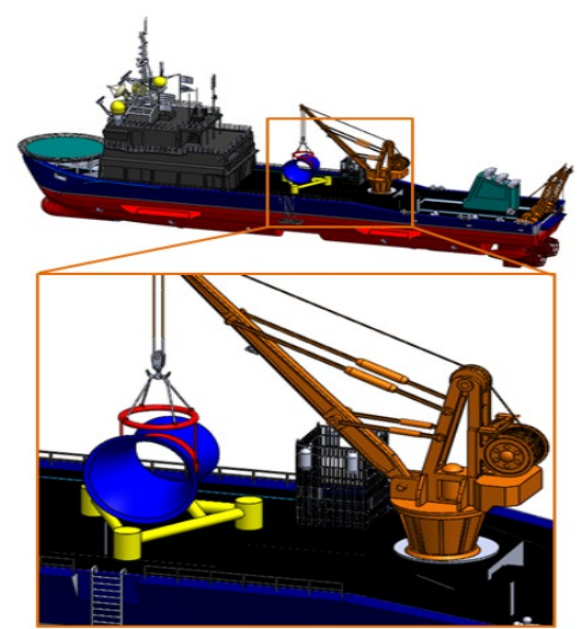

(b) our case of installation of the tidal turbine nozzle

Figure 4. Description of the installation system.

In our study, the diameter of the nozzle is about 20 meters. We have chosen as boundary conditions a belt-shaped encasement rolled up around a part of the nozzle. Figure 5 presents the fixed part, the hemispherical geometry of the impactor, and the overall model adopted for the simulation. The model presents the turbine section and the position of the impactor, Figure 5(c). In this case, the impactor is perpendicular to the nozzle. Indeed, the diameter of the impactor in our case is 1 meter, and its mass is about 1 ton.

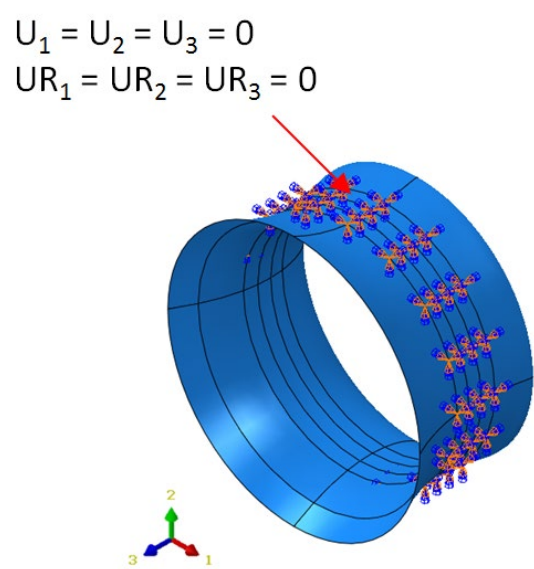

(a) Boundary conditions

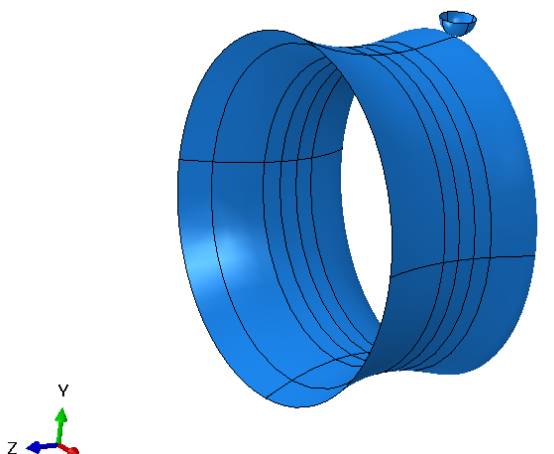

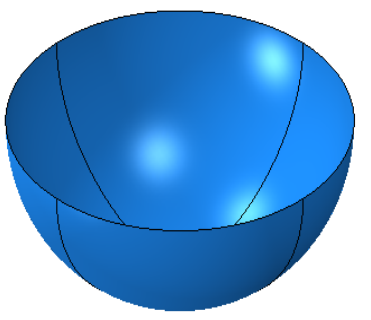<smiles>[Y]C([Y])[Y]</smiles>

(b) Hemispherical impactor

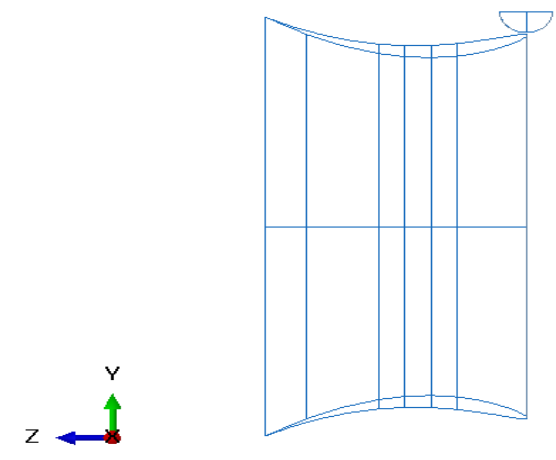

(c) The model of the impactor on the leading edge

Figure 5. Boundary condition, hemispherical impactor and the overall model.

\section{NUMERICAL MODELING OF THE STRUCTURAL RESPONSE OF THE NOZZLE USING FINITE ELEMENT METHOD}

In order to solve various problems related to the damage of composite structures in shipbuilding and to analyse their ruin, the Abaqus/Explicit software is suitable for the analysis of the issues with large deformations such as non-linear dynamic problems, as in an impact [1]. The hybrid composite nozzle is modelled in our numerical model as a deformable structure and meshed with the rigid quadrilateral S4R type element. In contrast, the impactor is modelled as a rigid body with a mass of 1 ton and a velocity of $8 \mathrm{~m} / \mathrm{s}$, which is set as an initial condition to the impactor at the reference point. To 
minimise the computation time and to optimise the mesh model without degrading the quality of the simulation results, a modelling strategy has been conducted which consists of defining an optimal mesh by verifying the convergence of the numerical model, as shown in Figure 6.

Figures 6(a) and 6(b) show the variation of maximum stress and maximum deflection, respectively, as a function of mesh density. The results of the calculations performed started to converge from 129490 elements with a mesh size of $100 \mathrm{~mm}$ long. Indeed, the convergence value is calculated according to a ratio of 'mesh size / total size of the structure' of 0.005 . It can be seen from Figure 6 that the more the mesh is refined, the maximum stress increases, and the maximum displacement decreases. In non-linear structural analyses, the use of quadratic elements is not desired for this kind of modelling because it demands a high computation time. For this reason, in our work, one opted to use a 4-node quadrilateral element with linear interpolation and reduced integration (S4R) which is known for its robustness. It is adapted to large applications and allows for better accuracy at a reduced cost using a fine mesh instead of a coarse mesh. Five types of hybrid composites were studied for a low-velocity impact (LVI), the total thickness of the laminate is 9.6 $\mathrm{mm}$, and the composite structure layup is $(0 / 45 / 90 / 45 / 0)_{3}$; in Figure 7.

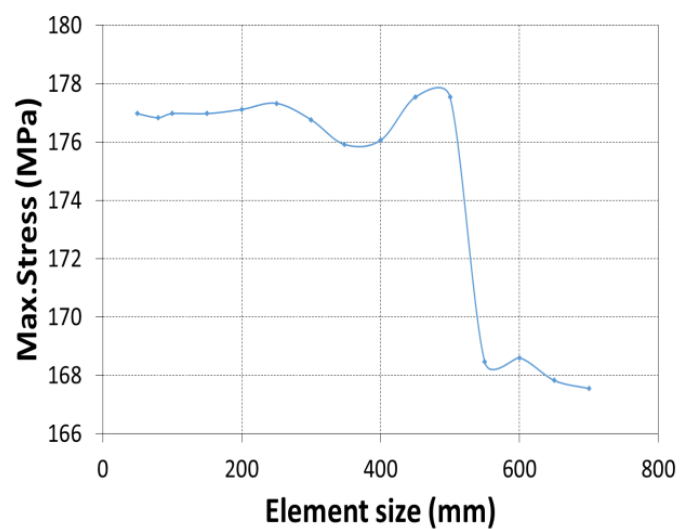

(a) Convergence of maximum stress

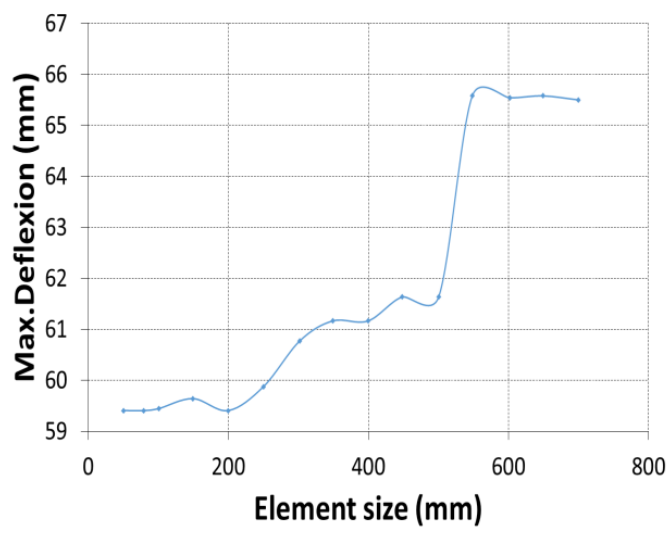

(b) Convergence of maximum deflexion

Figure 6. Mesh convergence.

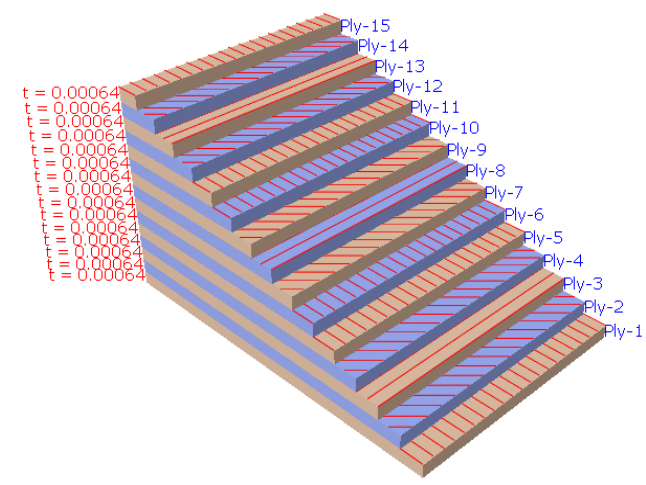

Figure 7. 15-ply laminate $(0.64 \mathrm{~mm} / \mathrm{ply})$.

\section{RESULTS AND DISCUSSION}

The results of finite element simulation are given in this section by evaluating the mechanical performance of the nozzle under low-velocity impacts on leading-edge zone during installation. The accidental impact situation was studied in a one-step process on the Abaqus software (an explicit dynamic step).

\section{Global Behaviour}

In this part, the energy variation of the CGG and CCC configurations are presented, Figure 8. All the curves of other configurations have the same trends, which is the reason for presenting only two configurations. The analysis of this energy variation proves the theory of energy conservation of our model. The results show that global energy stays stable during the entire duration of the calculation and meets to the wished energetic impact. Indeed, the internal and kinetic energies together represent the total energy. Furthermore, to validate the energy conservation theory the internal energy of the structure equals damage energy plus deformation energy.

The different energies have been identified as follows: ALLAE (artificial energy), ALLSE (strain energy), ALLDMD (damaging energy), ALLKE (kinetic energy), ETOTAL (total energy) and ALLIE (internal energy). 


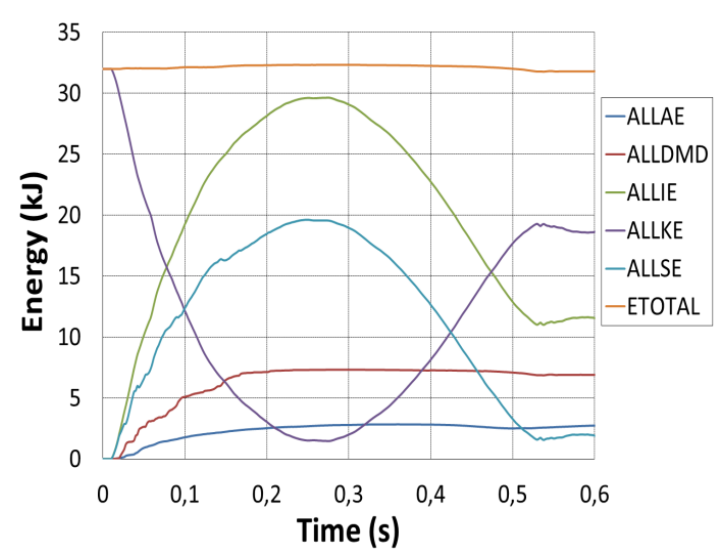

(a) $\mathrm{CCC}$

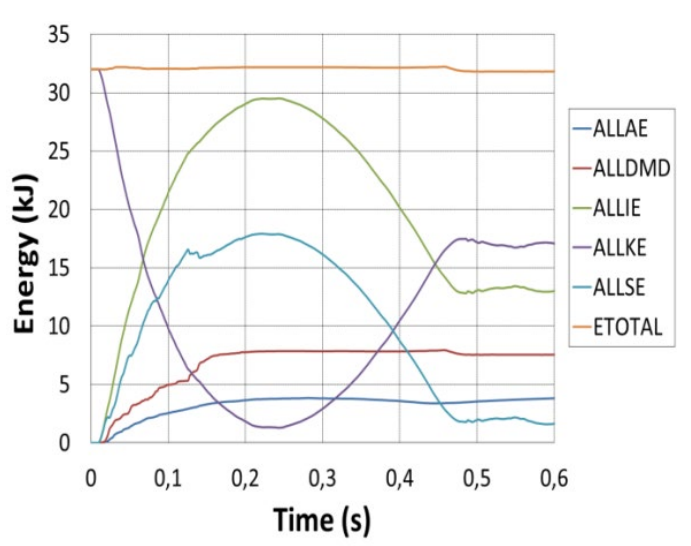

(b) $\mathrm{CGG}$

Figure 8. Impact energies versus time ( $\mathrm{m}=1$ tonne, $\mathrm{V}=8 \mathrm{~m} / \mathrm{s})$.

Figure 9 represents the damage energy vs time and maximum damage energy in the case of leading-edge impact. Figure 9(a) and 9(b) show that the configurations CCC, CGG are the less damaged and the most resistant. On the other hand, the GGC, GGG and GCG configurations are the most damaged due to the fact that the external surface of the CGG laminate is completely covered with the carbon fibre layer which is subject to severe contact stress and easily damaged during contact, while the GGG configuration due to the absence of carbon fibres, and GCG because of placing the carbon layer between two layers of glass. So, it can be concluded that, in the CGG configuration, the carbon layer is protected by two layers of glass fibre and give the most resistance for damage formation. These results demonstrate that the material acts elastically when the carbon fibre layer is situated on the internal surface.

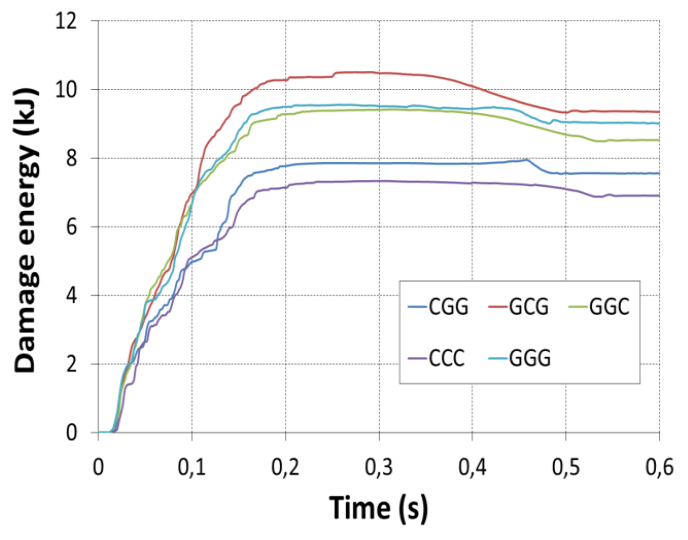

(a) Damage energy vs. time

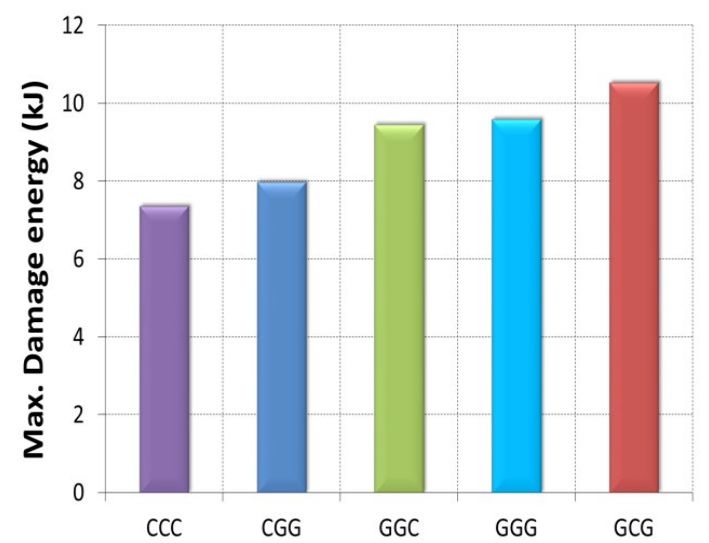

(b) Maximum damage energy

Figure 9. Evolution of damage in the tidal turbine nozzle.

Based on the energy level, drop-weight impact studies generally reveal three different modes of interaction between impactor and material. The projectile rebounds as the amount of energy absorbed by the composite is low. On the other hand, if the majority of the energy is absorbed by different modes of damage, no rebound achieved. Lastly, if the energy level is elevated, a perforation could be detected [13]. Figure 10 presents a standard energy curve for a drop-weight impact study where the impactor bounce happens.

For this research work, the majority of energy-time curves, as illustrated in Figure 11, are typically close to the one shown in Figure 10. During the impact study conducted, the rebound occurred for every hybrid composite studied. As can be seen from Figure 11, the hybrid composite GGC absorbs more than $30 \mathrm{~kJ}$ energy and also more than other types of configurations. The results of the previous section show that a large quantity of damage has formed in the GGC material. Thus, it is clear that this configuration absorbs more energy. However, CGG absorbs less energy due to its high stiffness, according to the results obtained. 


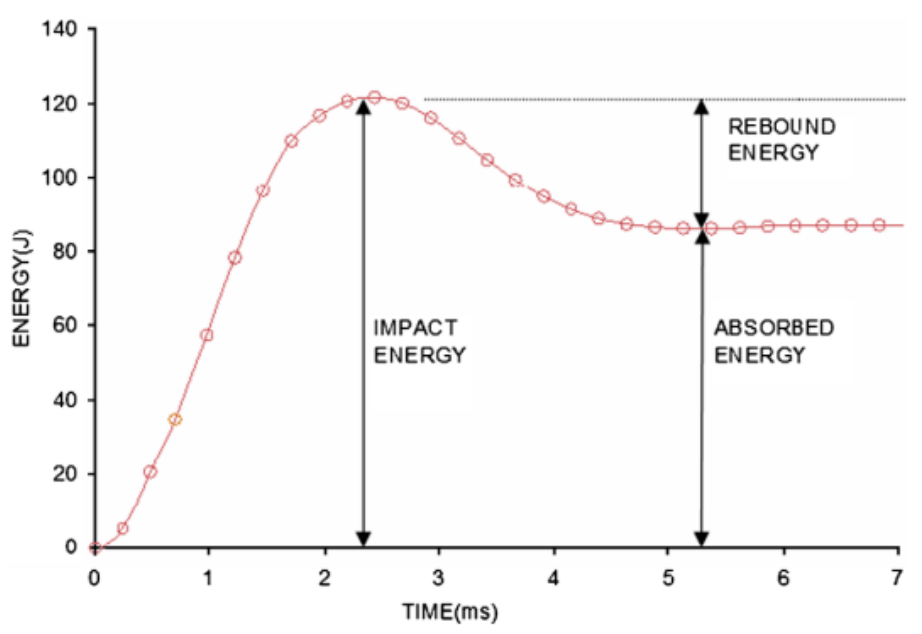

Figure 10. Energy curve in the case of the impactor rebound.

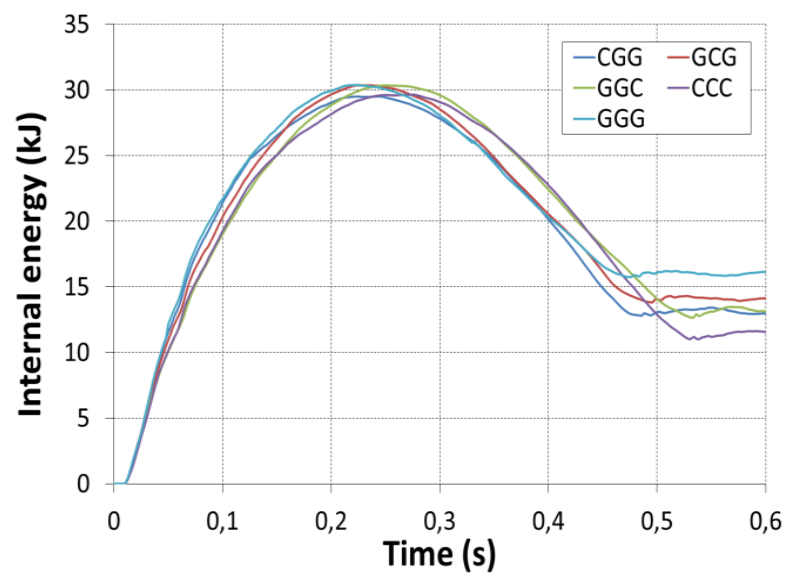

Figure 11. Energy-time curves of the five laminates.

\section{Impact Response Curves}

To evaluate the dynamic response and induced damage on a hybrid composite nozzle, the impact was realised with low velocity $(\mathrm{V}=8 \mathrm{~m} / \mathrm{s})$ on the leading-edge area of the nozzle. In this part, the progression and formation of damage seen in materials are presented. The force-time variations obtained during the LVI study for the five composite hybrids are shown in Figure 12.

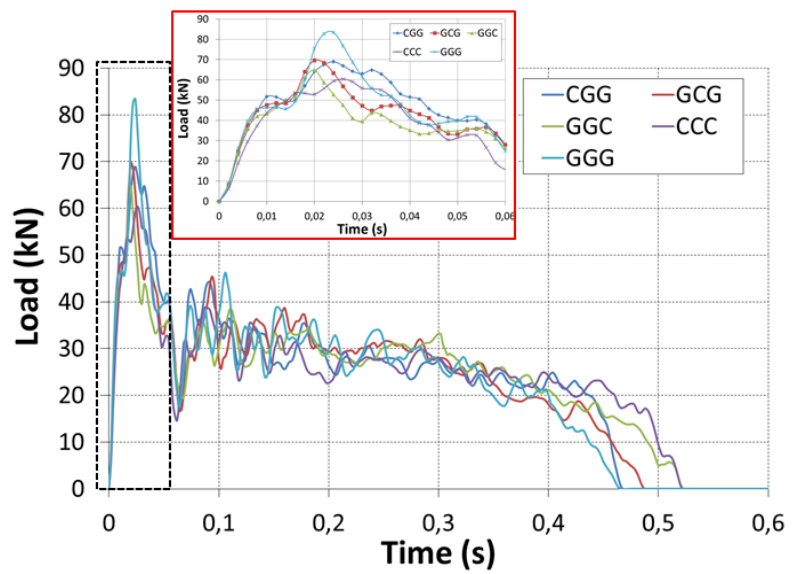

Figure 12. Force-time curves for the different materials applied.

Regarding the low-speed impact simulation results, the force-time curves of the five configurations were quite close to each other, as shown in Figure 12. An approximately linear increase succeeded by a fluctuating increase with a descending slope. Once the peak occurred, the force dropped along the curve with fluctuations and finally became nil. Indeed, the appearance of the first peak corresponds to the onset of damage formation, while the fluctuations indicate the formation of damage, whether in the form of matrix cracks or fibre breakage [14]. The total duration of impact was approximately 0.53 seconds, and the maximum force of the five configurations was between 0.02 and $0.03 \mathrm{~s}$, as indicated 
in Figure 12. As shown in Figure 13, the highest contact force is equal to $83.39 \mathrm{kN}$ and corresponds to GGG material, while the configuration CCC receives a minimum force of $60.39 \mathrm{kN}$.

As mentioned previously, the impact studies were carried out for an impact speed of $8 \mathrm{~m} / \mathrm{s}$. The curves of Figure 14 describe the variation of velocity during impact for the five configurations studied. This figure shows a rapid decrease in impactor velocity to a zero speed, which corresponds to the beginning phase of the elastic return. In this case, the impactor is probably hindered by the nozzle and consequently loses a large part of its kinetic energy in the form of nozzle deformation energy. It can also be observed from this figure that configurations GGG stabilises rapidly compared to other configurations. The principal cause behind this behaviour is that the response to the impact of the nozzle changes depending on its stacking sequence.

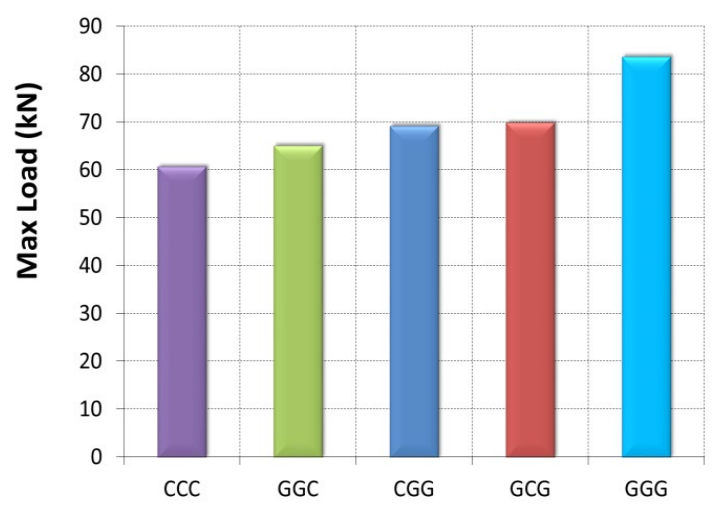

Figure 13. Maximum contact forces of the five configurations.

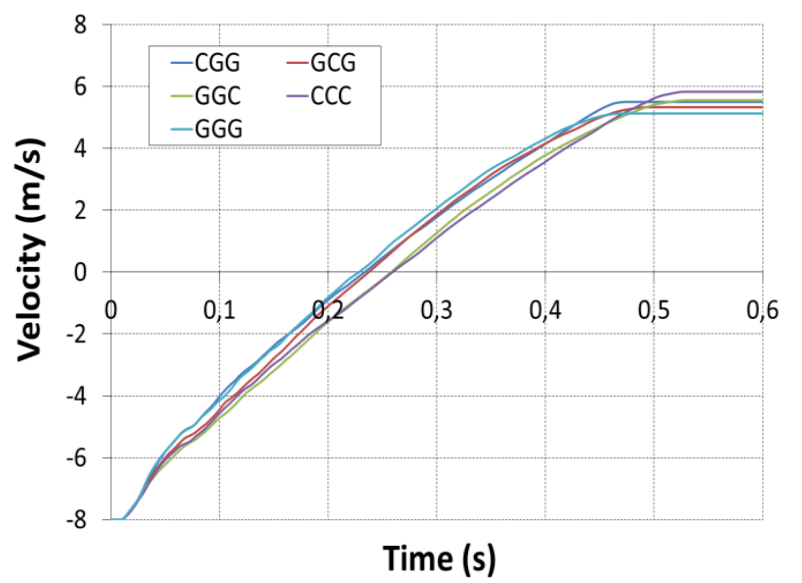

Figure 14. Leading-edge impact speed-time curves.

Figure 15(a) shows the evolution of the impactor displacement during the impact. The curves of contact force vs displacement for various configurations are illustrated in Figure 15(b). The area under the force-displacement graphs is considered equivalent to the energy absorbed by the hybrid composite material during impact. As shown in Figure 15(b), the laminates begin to displace vertically during contact with the impactor, and the force attains its highest level. Comparative analysis of the force-displacement variations of all five materials showed that the GGG configuration had the greatest maximum contact force and the CCC presented the lowest. However, at this energetic level of $32 \mathrm{~J}$, the minimum displacement values are found in the GGG configuration. In contrast, the greatest displacement value is observed in the CCC and GGC configurations as shown in Figure 15(a) and 15(c).

As shown in Figure 15(b), when the displacement has reached its peak value, the process of rebounding begins with a reduction of force. It can also be noted that once the force becomes nil, permanent deformation continues to be observed on GGG hybrid composite, while spring back is observed on other laminates. This shows that the layer on the exterior surface acts elastically and that the outer layer is especially undamaged. The fluctuations observed in Figure 15(b) indicate the damage formation on the laminates. 


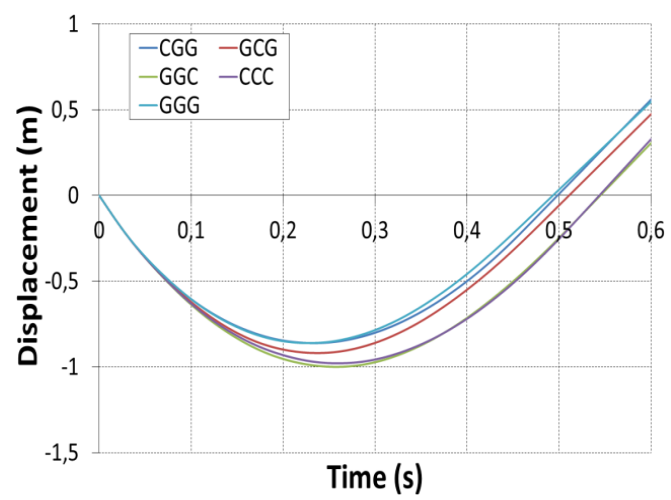

(a) displacement vs time

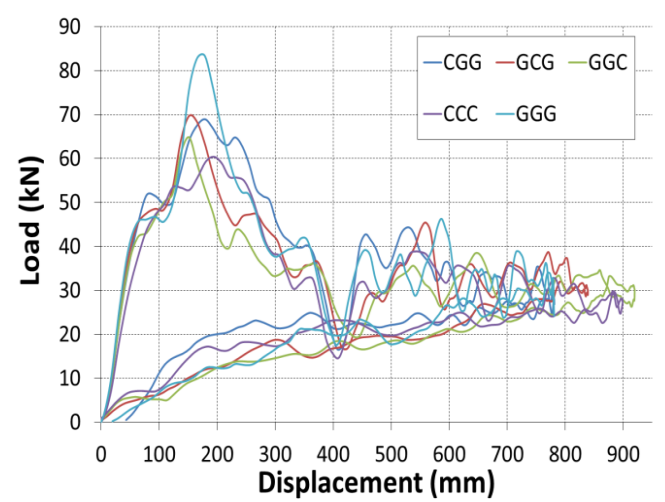

(b) variation of contact force vs displacement

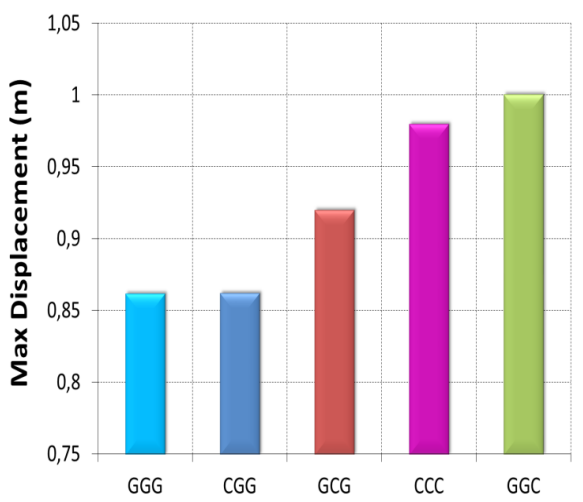

(c) maximum displacement

Figure 15. Results of the numerical simulation of the impact at low velocity (of $8 \mathrm{~m} / \mathrm{s}$ ).

\section{Damage in Compression}

According to the results in the previous sections, the CCC configuration was sufficiently resistant to impact, while GCG and GGG were the most damaged. For a better illustration of these results, Figure 16 and 17 show a comparative damage status of the fibres (DAMAGEFC) and matrix (DAMAGEMC) in compression of these three configurations. It can be seen that the size of the zones that concentrate the damage on the GCG and GGG laminates is larger than the size of CCC. Indeed, the damaged region of GCG and GGG has lengthened several millimetres compared to CCC.
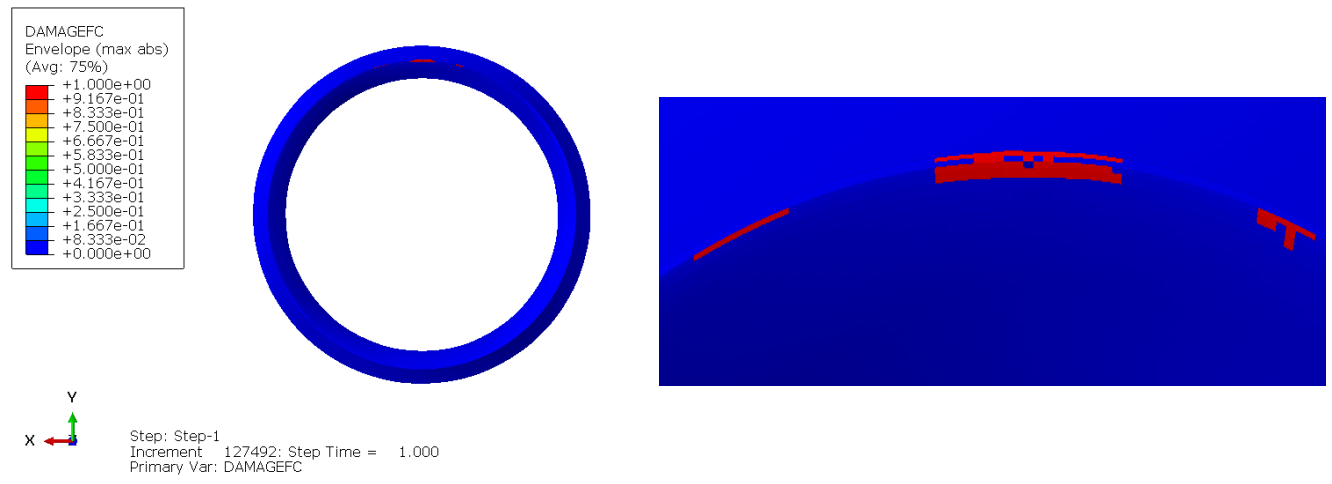

(a) GCC
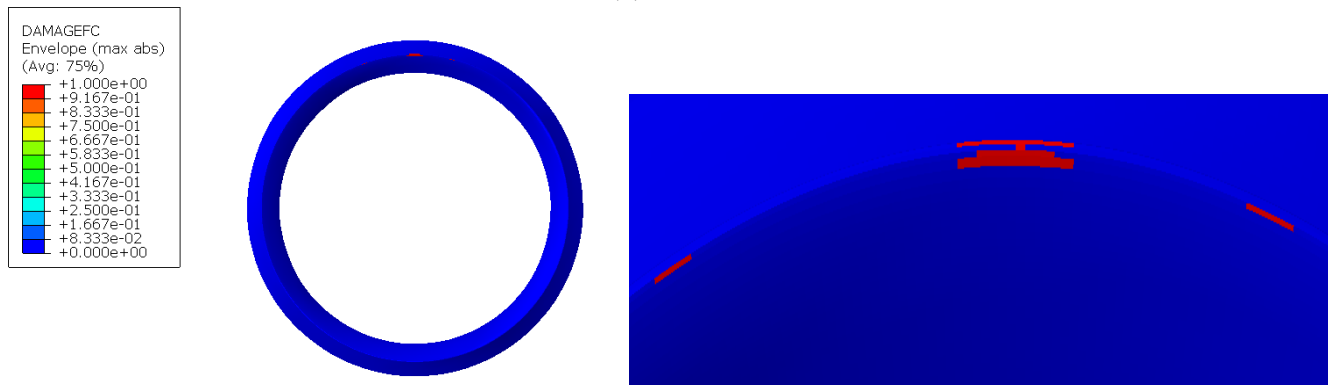

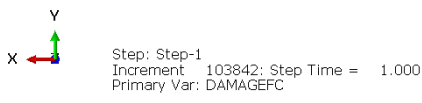

(b) $\mathrm{CCC}$ 

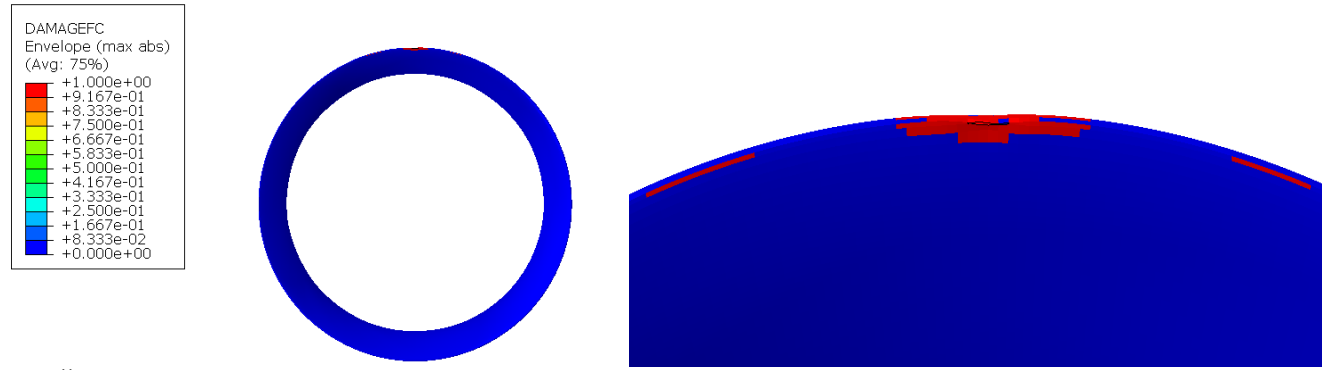

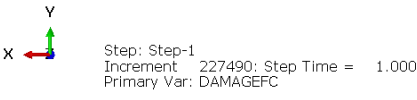

(c) GGG

Figure 16. Illustrative cartography of damage zones of laminate (DAMAGEFC).
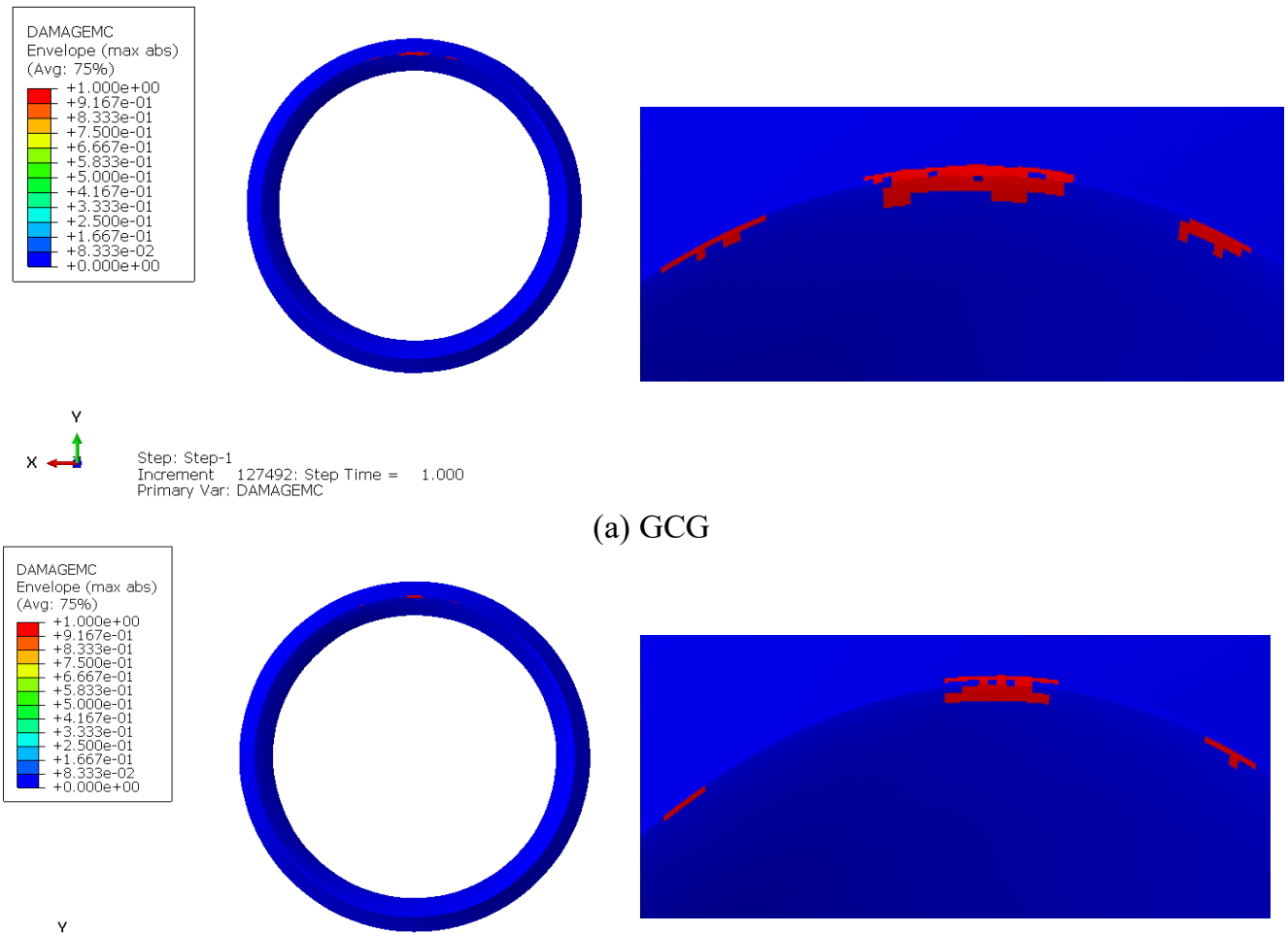

(a) GCG
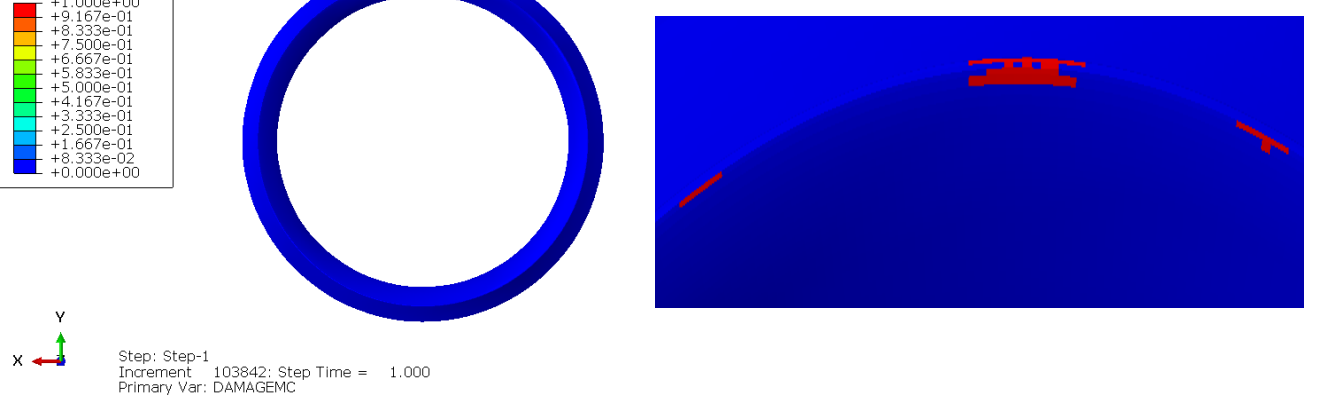

(b) $\mathrm{CCC}$
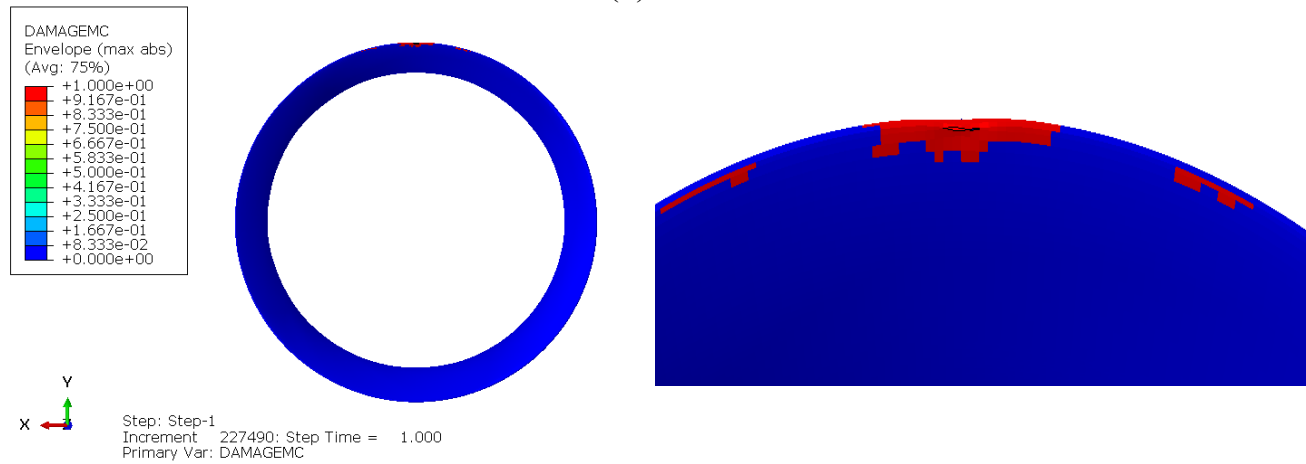

(c) GGG

Figure 17. Illustrative cartography of damage zones of laminate (DAMAGEMC).

\section{Damage in Tension}

Figure 18 illustrates the damaged zones of the tension fibres on the plies of GCG, CCC and GGG laminates. Similar behaviour compared to the fibres in tension was observed. Indeed, on the CCC laminate, the damage is null, while on the GCG laminate a slight increase was observed. 

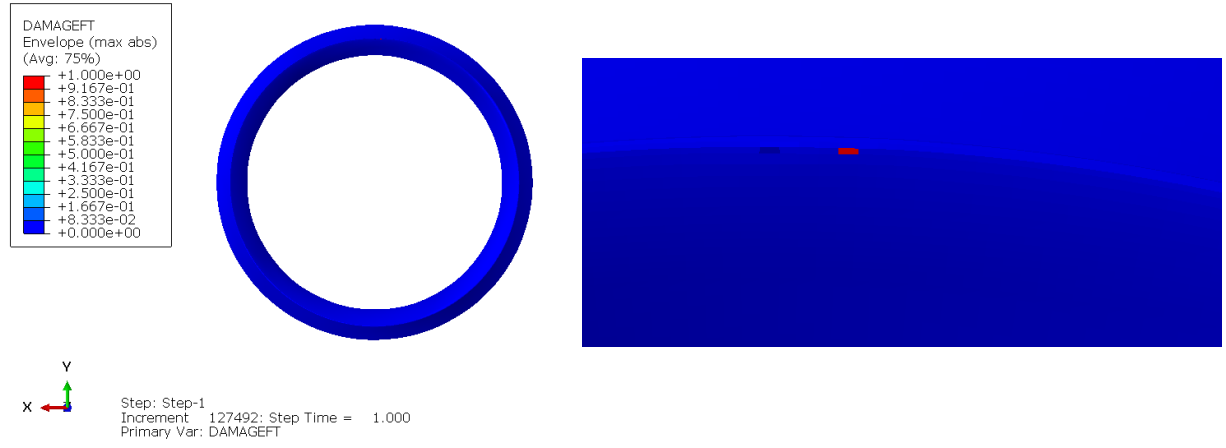

(a) GCG

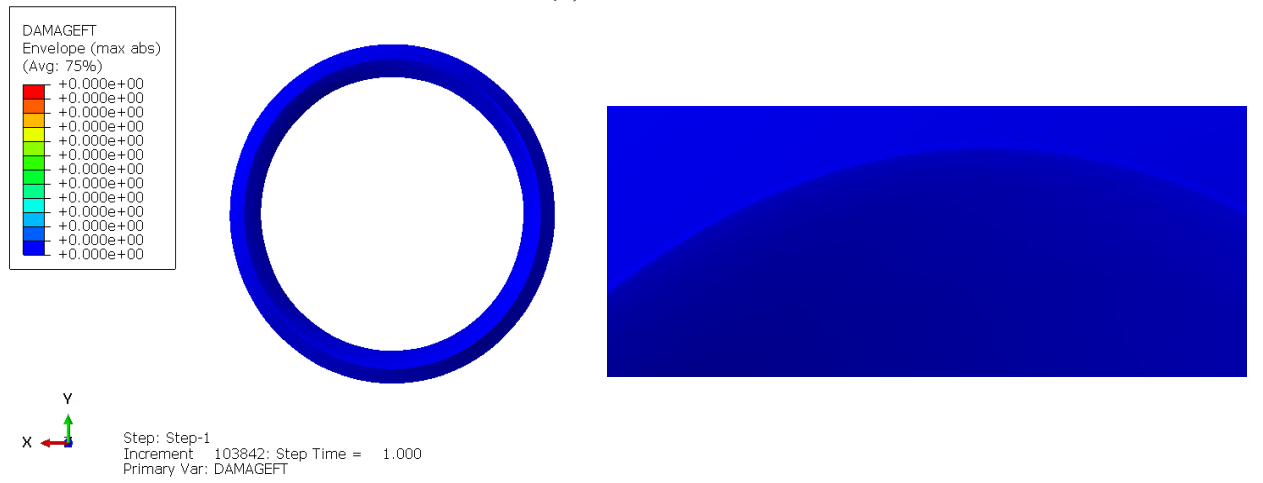

(b) $\mathrm{CCC}$
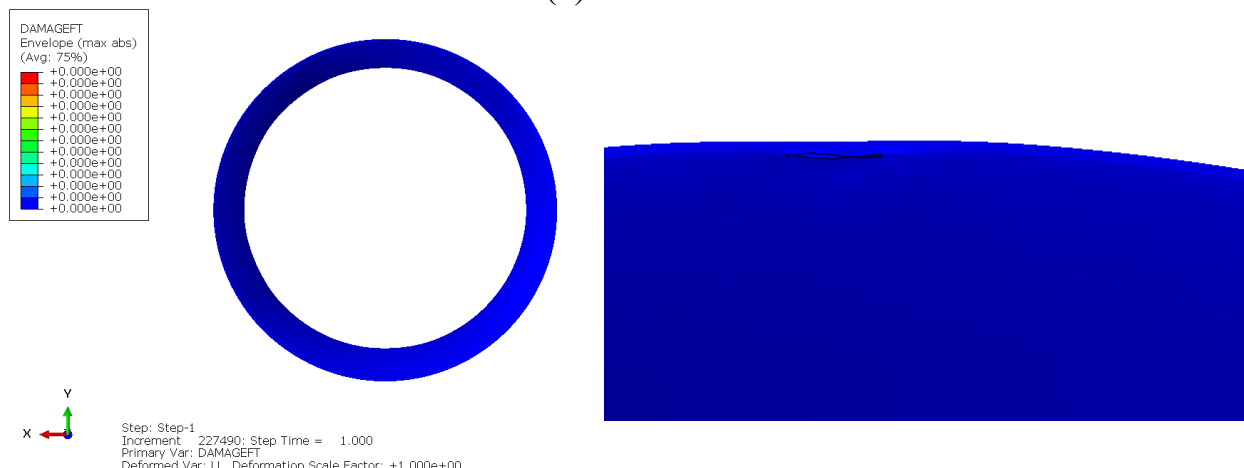

(c) GGG

Figure 18. Illustrative cartography of damaged zones of laminate (DAMAGEFT).

Figure 19 clearly illustrates the influence of impact on the behaviour of stratified layers. The damage to the tension matrix of the GCG and GGG configurations is more important; these areas extend from the impact region towards the extremities. The stress concentrations in these regions can promote the creation of a zone where the adjacent plies are delaminated. The appearance of this new damage mode and its development are susceptible to affect the mechanical performance of the structure.

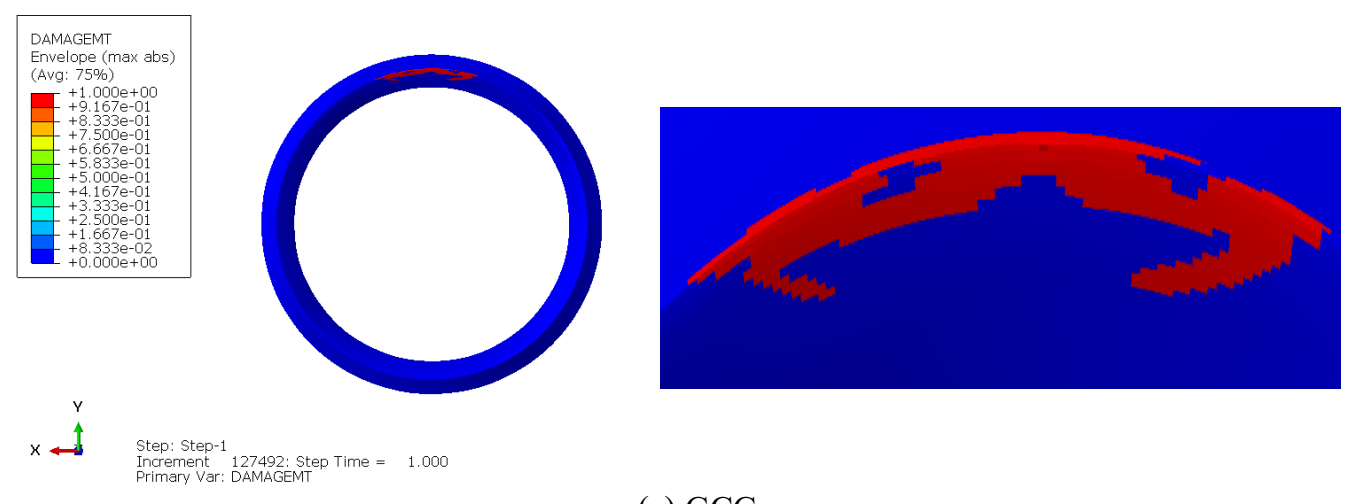

(a) GCG 


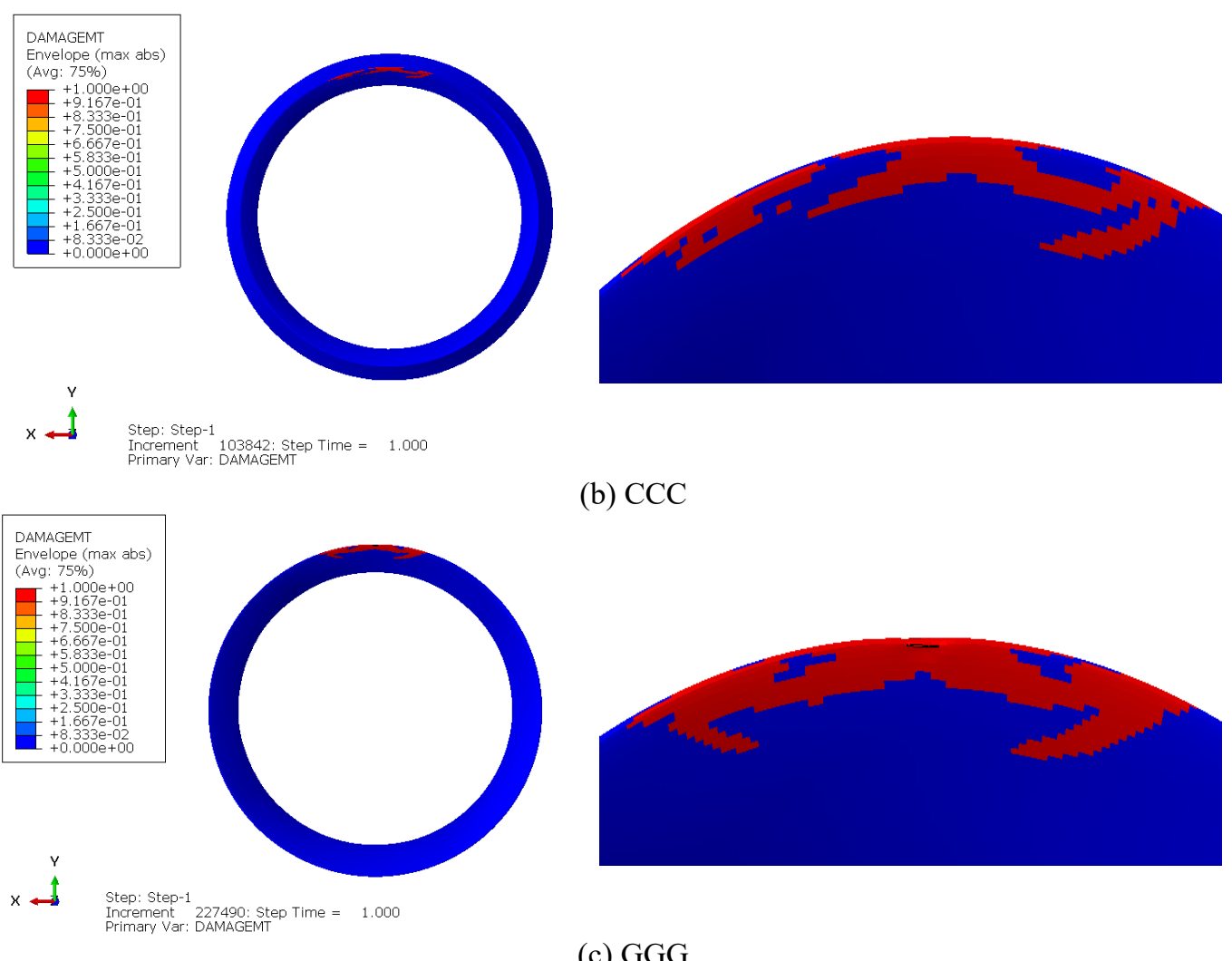

(c) GGG

Figure 19. Illustrative cartography of damage zones of laminate (DAMAGEMT).

\section{CONCLUSION}

The nozzle of a tidal turbine is generally exposed to accidental impacts during its installation. In this study, a numerical simulation of progressive damage was performed to predict the failure modes. Recourse to hybridisation is an excellent method to improve the fracture resistance of composite materials while keeping adequate mechanical performance for marine renewable energy applications. In this context, five types of hybrid configurations were adopted to identify the best stacking sequence permitting the formation of damage on the composite hybrid nozzle exposed to low-velocity impact. The Hashin criterion has been adopted to predict damage. The results showed that the stacking sequence has a significant effect on damage formation. The principal conclusions are as follows:

i. The values of the maximum contact force are obtained by the GGG laminate; it has been shown that this laminate cannot deform elastically. Thus, this resulted in an increase in energy absorption and an increase in the formation of damage.

ii. The formation of damage at the nozzle is dependent on the radial displacement during impact. In this work, the maximum displacement was achieved by the configurations CCC and GGC, and the minimum displacement was obtained by GGG configuration.

iii. The most damaged laminates are GGG and GCG. The CCC and CGG configurations are the most resistant. Indeed, These results demonstrate that the material acts elastically when the carbon layer is situated on the internal surface. In the CGG configuration, the carbon layer is protected through two layers of glass fibre and give the most resistance for damage formation. Subsequently, the glass layers protect the carbon layer.

iv. The modes of damage that can be observed in the hybrid nozzle are matrix cracking and fibre failure. All these modes are observed on the GGG configuration. However, only some damage modes have appeared in the CCC and CGG laminates.

v. During the simulation, the impact energy of the system is preserved and corresponds to the total energy for the five configurations.

vi. The next step of this work is to perform 3D modelling by using the technique of sub modelling. This technique makes it possible to focus on the area at risk and, to model the intralaminar damage (cracking of the matrix, rupture of the fibres) via a Vumat and interlaminar (delamination, rupture of the bonding zones) via the method of the cohesive zones. 


\section{ACKNOWLEDGEMENT}

The authors would like to thank the three anonymous reviewers for their insightful suggestions and careful reading of the manuscript.

\section{REFERENCES}

[1] Mahrez Ait Mohammed. Study of composites ducts for optimal design of an horizontal axis tidal turbine. PhD Thesis, ENSTA Bretagne, France, 2017.

[2] Santos P, Parente JP, Valvez S, et al. Hybridisation effect on the bending properties of flax composites. Procedia Structural Integrity 2020; 25: 370-377.

[3] Nachtane M, Tarfaoui M, Saifaoui D, El Moumen A, Hassoon OH, Benyahia H. Evaluation of durability of composite materials applied to renewable marine energy: Case of ducted tidal turbine. Energy Reports. 2018; 4: 31-40

[4] Nachtane M, Tarfaoui M, Ait Mohammed M, et al. Effects of environmental exposure on the mechanical properties of composite tidal current turbine. Renewable Energy 2020; 156: 1132-1145.

[5] Yu H, Longana ML, Jalalvand M, et al. Pseudo-ductility in intermingled carbon/glass hybrid composites with highly aligned discontinuous fibres. Composites Part A: Applied Science and Manufacturing 2015; 73: 35-44.

[6] Czél G, Wisnom MR. Demonstration of pseudo-ductility in high-performance glass/epoxy composites by hybridisation with thin-ply carbon prepreg. Composites Part A: Applied Science and Manufacturing 2013; 52: 23-30.

[7] Chavhan GR, Wankhade LN. Improvement of the mechanical properties of hybrid composites prepared by fibers, fiber-metals, and nano-filler particles-A review. In: Materials Today: Proceedings 2020; 27:78-82.

[8] Gemi L. Investigation of the effect of stacking sequence on low velocity impact response and damage formation in hybrid composite pipes under internal pressure. A comparative study. Composites Part B: Engineering 2018;153: 217-232.

[9] Sun G, Tong S, Chen D, et al. Mechanical properties of hybrid composites reinforced by carbon and basalt fibers. International Journal of Mechanical Sciences 2018; 148: 636-651.

[10] Damghani M, Ersoy N, Piorkowski M, et al. Experimental evaluation of residual tensile strength of hybrid composite aerospace materials after low velocity impact. Composites Part B: Engineering 2019; 179: 107537.

[11] Nachtane M, Tarfaoui M, El Moumen A, et al. Damage prediction of horizontal axis marine current turbines under hydrodynamic, hydrostatic and impacts loads. Composite Structures 2017; 170: 146-157.

[12] Tarfaoui M, Khadimallah H, Imad A, et al. Design and finite element modal analysis of $48 \mathrm{~m}$ composite wind turbine blade. Applied Mechanics and Materials 2011; 146: 170-184.

[13] Sevkat E, Liaw B, Delale F, et al. Drop-weight impact of plain-woven hybrid glass-graphite/toughened epoxy composites. Composites Part A: Applied Science and Manufacturing 2009; 40: 1090-1110.

[14] Wang H, vu-Khanh T. Damage extension in carbon fiber/PEEK crossply laminates under low velocity impact. Journal of Composite Materials 1994; 28: 684-707. 